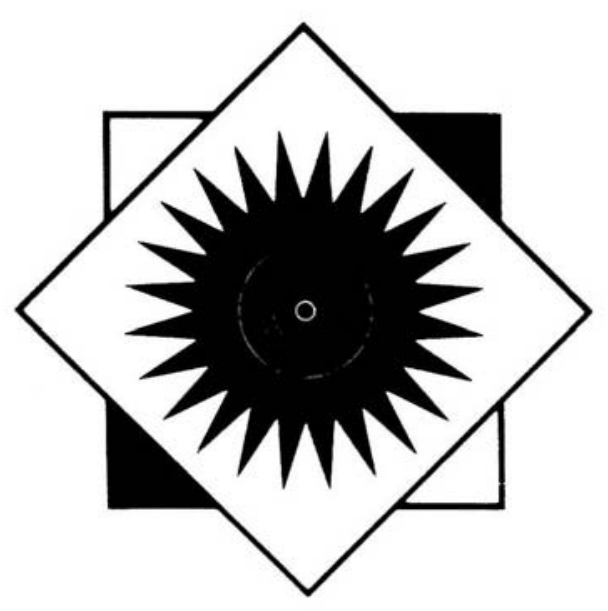

\title{
INNOVATIONS
}

\section{Library services through electronic mail}

\author{
By Miriam Bonham \\ Chairman, LIRN Task Force \\ Indiana University
}

At a time when it is becoming increasingly apparent that libraries and computing centers must work together to bring the fruits of the information age to their institutions, the Indiana University Libraries and the Bloomington Academic Computing Service (BACS) are cooperating in making a number of library services available through electronic mail.

Several library departments and branch libraries had been receiving and responding to inquiries informally via the campus electronic mail network for some time when, in the spring of 1986 , BACS acquired and installed a Vax 8600 computer dedicated to supporting information resources. The purpose of the new information system, named the Academic Information Environment (AIE), is to facilitate communication with the people and information sources needed to carry out faculty work productively. In August 1986, Elaine Sloan, dean of university libraries, proposed to Dan DeHayes, then dean of academic computing services, that the libraries expand and formalize the services they were offering through electronic mail into a Libraries Information and Reference Network (LIRN) as part of the AIE.

Following preliminary discussions, a design and development task force consisting of librarians and computing center personnel was formed in October 1986. The task force was named the LIRN task force and it was charged with identifying the functions to be included in LIRN, designing the applications including the menu screens for users, and implementing the applications necessary to provide ongoing maintenance. Library representatives were also charged with preparing library policies and procedures for review by appropriate library groups. We were asked to conclude the design phase by November 1 and to be ready to implement by January $1,1987$.
Concurrent with the work of the LIRN task force, the AIE was introduced, and 1,200 accounts were established for Indiana University Bloomington faculty. In December each faculty member, including library faculty, received a temporary password and user's guide explaining the AIE and how to access it.

The LIRN task force began its work by brainstorming for ideas of services that would be possible and desirable to provide electronically. We also requested all library staff to make suggestions for services to be provided on LIRN. Any service currently being provided over the telephone was a likely candidate. After discussing the ideas elicited, we sorted the most feasible and useful into four groups based on the date of implementation. Since we were charged to provide some services by January 1987, we decided to do first the things that either were easiest to program or were extensions of already available services.

We also took into account the degree of enthusiasm of the individuals who would need to work with the group. Most of the goals we set for the first time frame were achieved. However, we did not inaugurate LIRN until February to give time to test LIRN within the Libraries. There were no major problems, but a number of revisions were made as a result of suggestions from staff. The month of testing resulted in a better product for release on the Bloomington campus.

The extra month was also spent in staff training. Since most of the library staff had little or no experience with electronic mail, a member of the task force developed a brief, hands-on workshop that was conducted several times. The goal was to have at least one person in each unit trained. Presentations were given before various library groups to explain the procedures to be followed and to respond to concerns about the impact on services. 
We have continued to develop additional components and see this as an evolving process. The basic procedure followed in developing new components is as follows. First, the task force identifies a service provider and a contact person within that service to work with LIRN. The contact person is asked to describe in as much detail as possible the nature of the service to be provided and the information required from users. The contact is also asked to identify the logical steps in querying the user and to indicate if the information must be received in a particular format. Usually a task force member works with the contact, and both present the preliminary work to the task force for comments and suggestions. Usually there are revisions, after which the BACS representative on the task force prepares a prototype for evaluation online. Only after the task force and the affected service provider are satisfied with the component, is it added to LIRN.

The aim has been to provide simple, straightforward menu screens with ample help screens available and to design the system in such a way that users can focus on their needs rather than on the internal structure of the library. For instance, when requesting reference assistance or suggesting items for purchase, the user merely selects the appropriate subject from a list and the system routes the message to the proper place within the library. The user is not required to know or look up the individual or location responsible for that subject. To make the system work, BACS set up log-ins for each of the approximately 30 service points within the library so that a variety of personnel within larger units could access the system.

The service that had achieved the most success before implementation of LIRN was the Bloomington Delivery Service (BDS), a document delivery and table of contents service. Improvements were made based on previous experience, and growth has been steady with an ever increasing percentage of the requests being received electronically.

\section{Poster session presenters needed for BIS program}

The 1988 ACRL/BIS Conference Program Planning Committee invites applications from individuals involved in teaching CD-ROM to participate in a poster session. Approximately 15-20 applicants will be selected for the poster session, which will be held as part of a panel presentation scheduled for Sunday, July 10, 1988, from 2:00-5:30 p.m. Three or four individuals will be selected. Applications may be obtained by writing to: Esther Grassian, College Library Reference, 236A Powell Library Building, University of California, Los Angeles, CA 90024-1450; (213) 825-2138. Applications must be returned by December 1,1987 .
Another service offered was general information. Screens for each library unit or branch display such information as personnel, hours, telephone numbers, or services offered. Each unit is free to include whatever it wants, and it is responsible for keeping the data current; an attempt is made not to exceed a single screen.

Other services implemented in February 1987 were interlibrary loan requests, checking on the status of orders or receipt of materials, scheduling library tours, and suggestions.

Several additional services are in the process of deveopment, including loan renewals and class reserves. In addition, the task force is considering the possibility of providing access to other databases through the system. When the IU Libraries' online catalog, IO (Information Online), becomes operational, LIRN will provide one means of access.

In some ways it would have been preferable to have had the online catalog in place before offering other services such as ILL. However, by going ahead and providing some services through electronic mail, we gained the benefit of increased familiarity with microcomputers and terminals for library staff at all levels, and we started providing electronic services at the same time that the faculty are starting to use microcomputers and electronic mail in significant numbers.

A major goal for the campus is the scholar's workstation. Every faculty member will have a personal computer connected through networks to all of the resources necessary to conduct research and publish its results. The library and its collections and services must play a significant role in this development. We believe it has been an advantage to be early on the learning curve while usage is still small but expanding.

For the user, having library services offered through electronic mail means being able to request service 24 hours a day, 365 days of the year from home or office. There is no need to figure out which library department to call for answers and no more "telephone tag" trying to reach the right person. There isn't the immediacy of response that is possible through using the telephone, but each service point is required to check electronic mail at least twice a day and respond within 24 hours at the latest. If a message is initially received at an incorrect location, it is an easy matter simply to forward it to the correct destination. Although messages may have typing mistakes, less errors occur than when transcribing information received over the telephone.

A final, extremely important benefit has been the increased respect engendered between library and computing center personnel as a result of working together on this project. We have found that we share many similar goals and have complimentary skills for the tasks ahead of us as information providers. 